\section{Categorical perception, category boundary effects, and continuous perception: A reply to Hary and Massaro}

\author{
RICHARD E. PASTORE, \\ ROSEMARY SZCZESIUL, VIRGINIA WIELGUS, \\ KAREN NOWIKAS, and ROBERT LOGAN \\ State University of New York, Binghamton, New York
}

One of the earliest demonstrations of categorical perception for nonspeech stimuli was for a nominal rise-time continuum of sawtooth stimuli (Cutting \& Rosner, 1974). More recently, Rosen and Howell (1981) demonstrated that these original findings were the result of the specific set of stimuli employed, and when accurately created with a constant linear step size between stimuli, the rise-time continuum was perceived continuously. Among the several replications of the Rosen and Howell study, each with a unique elaboration, are Cutting's (1982) demonstration of categorical perception for the rise-time continuum with constant logarithmic step size and Hary and Massaro's (1982) study, which claimed to find categorical perception for an unusual "bipolar" continuum. We note here a number of problems with Hary and Massaro's study and their claim for a new theory of categorical perception (also see Massaro \& Hary, 1983).

\section{Categorical Perception Criteria}

Studdert-Kennedy, Liberman, Harris, and Cooper (1970) specified a set of operational criteria that have been generally accepted in the subsequent literature as the minimal conditions for demonstrating categorical perception. The criteria include: (1) distinct labeling categories with a sharp boundary, (2) a distinct peak in the discrimination function at the category boundary, (3) good agreement between the obtained discrimination function and the function predicted on from the labeling function, and (4) "troughs" of chance discrimination performance within each category. According to Studdert-Kennedy et al., only when all four criteria are met can there be a valid claim that perception is absolute, discrete, or categorical. It is not uncommon for researchers to obtain data that meet the first three of these criteria but fail to meet the critical fourth criterion; such noncategorical results are said to demonstrate a

This research was supported in part by Grants BNS8003704 and BNS8302873 from the National Science Foundation to R. E. Pastore. The authors thank Bruno H. Repp for his helpful comments on earlier drafts of this manuscript. Address reprint requests to Richard E. Pastore, Department of Psychology, SUNYBinghamton, NY 13901. phoneme boundary effect (Wood, 1976), or a category boundary effect (Pastore, 1981).

Although Hary and Massaro (1982; Massaro \& Hary, 1983) cite Studdert-Kennedy et al. (1970) as the basis for evaluating categorical perception, they ignore the operational criteria specified in that article; the criterion of chance discrimination within categories is never met by Hary and Massaro's data. With a $50 \%$ chance level, discrimination performance never was less than $60 \%$ for the bipolar continuum (see Figures 5 and 7 in Hary \& Massaro, 1982). Macmillan's (1983) reanalysis of the results from Experiment 2 found minimum d' values of 0.71 and 0.84 , which represents poor, but not chance, discrimination. Thus, while Hary and Massaro (1982) have demonstrated a category (or phoneme) boundary effect, they have not demonstrated categorical perception with their bipolar continuum.

\section{Number of Continua}

Categorical perception and category boundary effects are theoretically important when they are found for a single physical continuum (thus identifying unique characteristics of sensory or perceptual processing), but are trivial when based upon discontinuities inherent to physical dimensions. Our second problem thus concerns the nature of the "bipolar continuum." Most acousticians assume that the minimum rise time of a stimulus envelope is zero, representing an infinite rate of change in theoretical envelope amplitude at onset. Hary and Massaro claim to have extended the rise-time continuum to negative values, creating their "bipolar continuum of onset times." It is our contention that the "bipolar continuum" is not a single continuum, but rather represents the juxtaposition of two different physical continua. The two continua are illustrated in Figure 1 . The positive onset-time continuum varies in the duration of the linear increase in signal envelope amplitude from onset to its maximum, as illustrated in the lower position of Figure 1 for onset times of $+0,+15$, and $+30 \mathrm{msec}$. The negative onset-time continuum has a constant rise time of approximately $0.8 \mathrm{msec}(1 / 4$ cycle of a $294-\mathrm{Hz}$ tone) to a maximum envelope amplitude (which is twice the maximum for the positive rise-time continuum), then falls linearly by $50 \%$ over the nominal negative onset time, as illustrated in the upper position of Figure 1 for "onset times" of $-0,-15$, and $-30 \mathrm{msec}$. Note that the negative onset-time stimuli always have an additional high-amplitude (constant rise time) burst at onset and that they vary only in the fall time of this extra energy. The positive onset-time stimuli meet the typical definition for a rise-time continuum and do not have the added onset energy. It is difficult to make a 


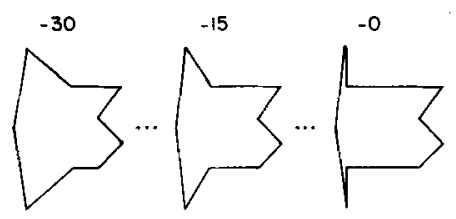

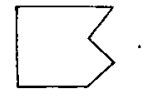

$+0$

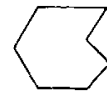

$+15$

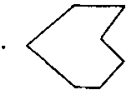

$+30$
Figure 1. Theoretical onset envelope of negative onset-time continuum (upper stimuli) and positive onset-time continuum based upon Hary and Massaro (1982). The actual envelope of the waveform may differ from the theoretical envelope, depending upon the frequency of the stimulus and the characteristics of the transducer used to generate the sound.

strong case that the initial rise-time and initial falltime continua are part of a single onset-time continuum.

Some evidence that Hary and Massaro's bipolar onset-time continuum really comprises two different continua can be found by examining the 0 -msec stimulus. This should be a single stimulus common to the positive and the negative portions of the continuum, yet, as illustrated in Figure 1, each continuum has its own theoretical 0 -msec stimulus. ${ }^{1}$ The +0 onset-time stimulus lacks the extra high-amplitude onset burst that characterizes the negative onset-time stimuli, but, unlike the other positive stimuli, the +0 stimulus possesses the rapid onset characteristic of negative onset-time stimuli (probably accounting for the $80 \%$ discriminability that Hary \& Massaro found between the +0 - and $+30-\mathrm{msec}$ stimuli). All negative onsettime stimuli (including $-0 \mathrm{msec}$ ) differ from the +0 onset-time stimulus in terms of a high-amplitude spike or click at onset. Not only are these two theoretical versions of the $0-\mathrm{msec}$ onset-time stimulus physically different, but, as we shall see, they are perceptually different.

The "bipolar continuum" of Hary and Massaro consisted of onset times of $-60,-45,-30,-15,+0$, $+15,+30,+45$, and $+60 \mathrm{msec}$ (see Figure 1). Using the rules described by Hary and Massaro (1982), we synthesized stimuli with positive and negative rise times of $0,15,30$, and 60 msec. All stimuli were 750msec segments of $294-\mathrm{Hz}$ tones and had onsets at positive waveform zero-crossings. The stimuli decreased linearly in amplitude beyond the critical onset characteristics. Using a variable-standard (roving level) AX procedure, we asked four psychophysically experienced subjects (who were naive as to the purpose of the research) to discriminate the stimulus pairs of $-60 /-30,-60 /-15,-0 /+0,+15 /$ +60 , and $+30 /+60$. The stimuli were presented binaurally over TDH-49 earphones at a peak intensity of $75 \mathrm{dBA}$. The subjects were run in pairs in a commercial sound chamber. The results are summarized in terms of both percent correct (Table 1) and d' (Table 2) calculated with the procedure and table developed by Kaplan, Macmillan, and Creelman (1978). Except for Subject D, who had difficulty with all stimulus pairs, the subjects discriminated the nominally equivalent $-0 /+0$ comparison far better than they did stimuli that differed in onset time by $30 \mathrm{msec}$ and also, in most instances, better than stimuli that differed by $45 \mathrm{msec}$. Clearly, the -0 and +0 stimuli are not perceptually equivalent. These results support our conjecture that the bipolar onset-time continuum is not one continuum, but rather the combination of two very different continua.

\section{Comparison to Earlier Theories}

Pastore, Ahroon, Baffuto, Friedman, Puleo, and Fink (1977) proposed that there is a tendency to find either categorical perception or the category boundary effect "whenever there is a relatively precise, stable reference along a continuum ... [which provides] greater information to the system for discriminating between stimuli than would be available elsewhere on the continuum" (Pastore, 1981, p. 182). This earlier proposal clearly claims that categorical perception and the category boundary effect need not be absolute, but rather need only represent a significant difference in the degree of information available to the subject for discriminating pairs of betweencategory stimuli relative to discriminating pairs of within-category stimuli. In this view, the difference between categorical perception and the category boundary effect is the amount of information available to the subjects in discriminating within-category stimuli pairs. Although Hary and Massaro clearly did not find categorical perception, their results generally were consistent with this earlier model of categorical

Table 1

Percent Correct Discrimination for Pairs of Stimuli Differing in Rise-Time or Onset-Time Characteristics for the Four Subjects

\begin{tabular}{cccccc}
\hline Subject & $-60 /-30$ & $-60 /-15$ & $-0 /+0$ & $+60 /+15$ & $+60 /+30$ \\
\hline A & 48.0 & 50.0 & 82.8 & 83.1 & 68.0 \\
B & 47.5 & 49.4 & 84.2 & 74.4 & 56.2 \\
C & 47.0 & 53.4 & 70.5 & 56.2 & 50.0 \\
D & 56.3 & 55.3 & 50.7 & 57.6 & 46.9 \\
Mean & 49.7 & 52.0 & 72.1 & 67.8 & 55.3 \\
\hline
\end{tabular}

Table 2

d' Calculated From Data Summarized in Table 1 as Percent Correct

\begin{tabular}{crrrrr}
\hline Subject & $-60 /-30$ & $-60 /-15$ & $-0 /+0$ & $+60 /+15$ & $+60 /+30$ \\
\hline A & 1.40 & .00 & 3.58 & 3.33 & 3.06 \\
B & -1.43 & -.86 & 3.66 & 2.78 & 1.47 \\
C & -1.21 & 1.10 & 2.36 & 1.52 & .00 \\
D & 1.13 & 1.24 & .03 & 1.38 & -.74 \\
Mean & -.03 & .37 & 2.41 & 2.25 & .95 \\
\hline
\end{tabular}


perception. Miller, Wier, Pastore, Kelly, and Dooling (1976) conjectured that categorical perception might be due to some form of absolute threshold, with suprathreshold discrimination possibly following Weber's law. Both Carney, Widin, and Viemeister (1977) and Samuel (1977) demonstrated better than chance discrimination within categories following practice. These studies and others (e.g., Hanson, 1977; Macmillan, Kaplan, \& Creelman, 1977; Pisoni \& Lazarus, 1974) have either explicitly or implicitly claimed that the first three, if not all four, of the operational criteria for categorical perception (StuddertKennedy et al., 1970) can be met without the need for perception to be discrete or categorical. Hary and Massaro's (1982) argument clearly is consistent with, rather than "in contrast with ... [the] viewpoints" (p. 418) expressed over the last decade.

\section{Conclusions}

The Hary and Massaro (1982) study has demonstrated a category boundary effect, but not categorical perception, for the relatively uninteresting case of stimuli that are noncontinuous in their physical characteristics. Although these results may be relevant to modeling listeners' behavior in the context of distinct anchors and changing stimulus ranges (as noted by Macmillan, 1983), they are largely tangential to issues concerning the nature of categorical perception. Hary and Massaro's conclusion that categorical perception results need not indicate absolute perceptual categories has been reached by many researchers who have published over the last decade, and it stands quite independent of Hary and Massaro.

\section{REFERENCES}

Carney, A. E., Widin, B., \& Viemeister, N. (1977). Noncategorical perception of stop consonants differing in VOT. Journal of the Acoustical Society of America, 62, 961-970.

Cutring, J. E. (1982). Plucks and bows are categorically perceived, sometimes. Perception \& Psychophysics, 31, 462-476.

Cutring, J. E., \& Rosner, B. S. (1974). Categories and boundaries in speech and music. Perception \& Psychophysics, 16, 564-570.

Hanson, V. L. (1977). Within-category discriminations in speech perception. Perception \& Psychophysics, 21, 423-430.

HarY, J. M., \& Massaro, D. W. (1982). Categorical results do not imply categorical perception. Perception \& Psychophysics, 32, 409-418.

Kaplan, H. L., Macmillan, N. A., \& Creelman, C. D. (1978). Tables of $d^{\prime}$ for variable-standard discrimination paradigms. Behavior Research Methods \& Instrumentation, 10, 796-813.

Macmillan, N. A. (1983). A psychophysical interpretation of a "categorical perception" experiment by Hary and Massaro. Perception \& Psychophysics, 34, 494-498.

Macmillan, N. A., Kaplan, H. L., \& Creelman, C. D. (1977). The psychophysics of categorical perception. Psychological Review, 84, 452-471.

Massaro, D. W., \& HarY, J. M. (1983). Speech perception and psychophysics: Theory and experiment. Perception \& Psychophysics, 34, 499.502.

Miller, J. D., Wier, C. C, Pastore, R. E., Kelly, W. J., \& Dooling, R. J. (1976). Discrimination and labeling of noisebuzz sequences with varying noise-lead times: An example of categorical perception. Journal of the Acoustical Society of America, 60, 410-417.

Pastore, R. E. (1981). Possible psychoacoustic factors in speech perception. In P. D. Eimas \& J. L. Miller (Eds.), Perspectives on the study of speech. Hillsdale, NJ: Eribaum.

Pastore, R. E., Ahroon, W. A., Baffuto, K. J., Friedman, C., Puleo, J. S., \& Fink, E. A. (1977). Common-factor model of categorical perception. Journal of Experimental Psychology: Human Perception \& Performance, 3, 686-696.

Pisoni, D. B., \& Lazarus, J. H. (1974). Categorical and noncategorical modes of speech perception along the voicing continuum. Journal of the Acoustical Society of America, 55, 328-333.

Rosen, S. A., \& Howell, P. (1981). Plucks and bows are not categorically perceived. Perception \& Psychophysics, 30, 156-168.

SAmUEL, A. G. (1977). The effect of discrimination training on speech perception: Noncategorical perception. Perception \& Psychophysics, 22, 321-330.

Studdert-Kennedy, M., Liberman, A. M., Harris, K. S., \& COOPER, F. S. (1970). Motor theory of speech perception: A reply to Lane's critical review. Psychological Review, 77, 234-249.

Woob, C. C. (1976). Discriminability, response, bias, and phoneme categories in discrimination of voice onset time. Journal of the Acoustical Society of America, 60, 1381.

\section{NOTE}

1. If the nominal 0 -msec rise time of the negative onset-time stimuli and the +0 -msec stimulus were reduced to a true zero value, the theoretical difference between the -0 and +0 -msec stimuli would be eliminated. However, the earphone and auditory systems have their own inertias and cannot perfectly follow the instantaneous changes in either initial position or initial velocity of the theoretical waveform that would be required by a true 0 - $\mathrm{msec}$ rise time. An attempt to alter the "negative" and 0-msec onsettime stimuli to a true 0-msec envelope rise-time would represent an unreasonable demand on the ability of these transducer systems. The resulting distortion probably would create sufficient consistent stimulus differences to further improve the already very good discriminability between the highly distorted $+0-\mathrm{msec}$ stimulus and the relatively distortion-free positive onset-time stimuli. This modification in stimulus specification certainly would not avoid the strong argument against the fall-time continuum (even if superimposed on the +0 -msec stimulus immediately after stimulus onset) being an extension of the rise-time continuum.

(Manuscript received February 15, 1984; accepted for publication March 6, 1984.) 